American Journal of Applied Sciences 7 (11): 1495-1499, 2010

ISSN 1546-9239

(C) 2010 Science Publications

\title{
Improvement of Transient Stability of Power System by Thyristor Controlled Phase Shifter Transformer
}

\author{
Prechanon Kumkratug \\ Division of Electrical Engineering, Faculty of Engineering at Si Racha, \\ Kasetsart University, 199 M.6, Tungsukhla, Si Racha, Chonburi, 20230, Thailand
}

\begin{abstract}
Problem statement: The improvement of transient stability of the power system was one of the most challenging research areas in power engineer. Approach: This study presents the method to improve transient stability of power system by Thyristor Controlled Phase Shifter Transformer (TCPST). The mathematical model of power system equipped with a TCPST was systematically derived. The parameters of TCPST are modeled into power flow equation and thus it was used to determine control strategy. The swing curves of the three phase faulted power system without and with a TCPST are tested and compared in various cases. Results: The swing curve of system without a TCPST gets increases monotonically and thus the system can be considered as unstable whereas the swing curves of system with a TCPST can return to stable equilibrium point. Conclusion: From the simulation results, the TCPST can increase transient stability of power system.
\end{abstract}

Key words: Power system, transient stability, FACTS devices, shunt transformer, injected current, Unified Power Flow Controller (UPFC), TCPST, series transformer, voltage source, leakage reactance, control strategy, complex power

\section{INTRODUCTION}

Transient stability improvement is one of the important aspects in modern power system. The innovative Flexible AC Transmission System (FACTS) devices have been proposed during the last three decades for improving transient stability of power systems (Barbuy et al., 2009). There are various forms of FACTS devices such as Static Synchronous Series Compensator (SSSC), Static Synchronous Compensator (STATCOM), Unified Power Flow Controller (UPFC) and Inter line Power Flow Controller (Bhownick et al., 2009; Hannan et al., 2009; Magaji and Mutafa, 2009; Zhang, 2003; Leon and Zanetta, 2008; Parimi et al., 2008; Azbe and Mihalic, 2008).

A Thyristor Controlled Phase Shifter Transformer (TCPST) consists of a shunt transformer, a series transformer and a converter. The classification of TCPPS depends on the type of converter used. The converter can be of ac-ac bridge type, Pulse-Width Modulation (PWM) type, ac controller type (Badran et al., 2008; Daut et al., 2006). To verify the capability of TCPST on transient stability improvement, its suitable mathematical model and control strategy are needed to be presented.

This study presents the mathematical model of power system equipped with a TCPST. The presented mathematical model is applied to design control strategy of a TCPST. The simulation results are tested on a Single Machine Infinite bus system.

\section{MATERIALS AND METHODS}

Mathematical model: Figure 1a shows the schematic diagram of the Thyristor Controlled Phase Shifter (TCPS). The series transformer injects the voltage in series in the system. The active and reactive power injected by the series transformer is taken from the shunt transformer. For sake simplicity of analysis, the insignificant losses from transformer and converter is neglected. Thus the net complex power (real and reactive power) exchange between the TCPS and the system is zero. The injection of this complex power depends on the injection of a series voltage controlled by a converter.

Figure 1b shows the equivalent circuit of Fig. 1a. $\mathrm{V}_{\mathrm{s}}$ and $\mathrm{V}_{\mathrm{sh}}$ are represented by the synchronous voltage sources in series and shunt, respectively. $X_{\text {sh }}$ is the leakage reactance of the shunt transformer. $X_{s}^{\prime}$ is the leakage reactance seen from primary side of series transformer is given by $X_{s}^{\prime}=X_{s}+n^{2} X_{s h}$ where $n$ is the turn ratio number of the shunt transformer and $X_{s}$ is the leakage reactance of the series transformer. 


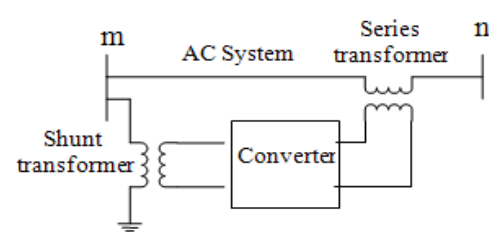

(a)

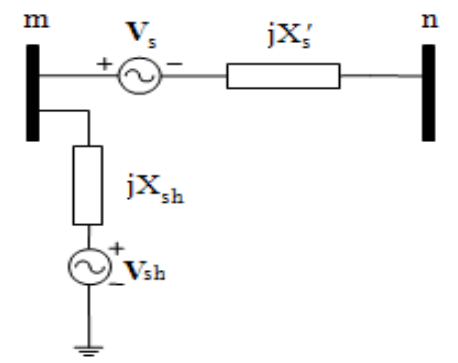

(b)

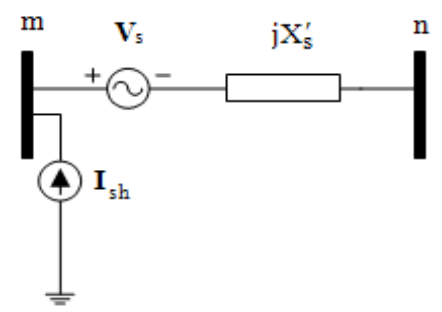

(c)

Fig. 1: A system equipped with TCPST; (a) Schematic diagram of a TCPST; (b) a series and shunt synchronous voltage source equivalent; (c) a series injected voltage source and a shunt injected current source

The shunt synchronous voltage source with leakage reactance can be represented by a shunt injected current model $\left(I_{\text {sh }}\right)$ as shown in Fig. 1c. A shunt injected current is composed of in phase current $\left(I_{p}\right)$ and in quadrature current $\left(I_{q}\right)$ which respect to the $V_{m}$. Thus $I_{\text {sh }}$ is given by:

$$
I_{s h}=\left(I_{p}-j I_{q}\right) e^{j \theta_{m}}
$$

Consider the single machine infinite bus system equipped with a TCPS at bus $m$ as shown in Fig. $2 a$ and $2 b$ shows the equivalent circuit of Fig. $2 a$. Note that $X_{1}$ is the sum of generator transient reactance, transformer leakage reactance and equivalent reactance of line 1 and $2 ; X_{2}$ is the equivalent reactance of $X_{s}^{\prime}$, line 3 and 4 . The complex power injected by the series transformer can be written as:

$\mathrm{S}_{\mathrm{s}}=\mathrm{V}_{\mathrm{s}}(-\mathrm{I})^{*}=\mathrm{V}_{\mathrm{s}}\left[\frac{-\mathrm{V}_{\mathrm{m}}+\mathrm{V}_{\mathrm{s}}+\mathrm{E}_{2}}{\mathrm{j} \mathrm{X}_{2}}\right]^{*}$

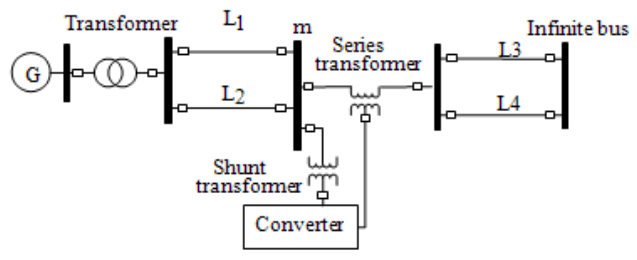

(a)

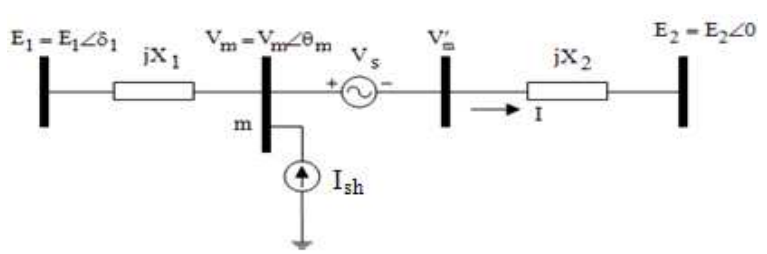

(b)

Fig. 2: A simple single machine infinite bus system with a TCPST; (a) single line diagram; (b) equivalent circuit

The active $\left(\mathrm{P}_{\mathrm{s}}\right)$ and reactive $\left(\mathrm{Q}_{\mathrm{s}}\right)$ powers injected by the series transformer are given by:

$$
\begin{aligned}
\mathrm{P}_{\mathrm{s}} & =\mathfrak{R}\left[\mathrm{S}_{\mathrm{s}}\right] \\
& =b \mathrm{~V}_{\mathrm{s}} \mathrm{V}_{\mathrm{m}} \sin \left(\theta_{\mathrm{s}}-\theta_{\mathrm{m}}\right)-\mathrm{bV}_{\mathrm{s}} \mathrm{E}_{2} \sin \left(\theta_{\mathrm{s}}\right) \\
\mathrm{Q}_{\mathrm{s}} & =\mathfrak{I}\left[\mathrm{S}_{\mathrm{s}}\right] \\
& =-\mathrm{bV}_{\mathrm{s}} \mathrm{V}_{\mathrm{m}} \cos \left(\theta_{\mathrm{s}}-\theta_{\mathrm{m}}\right)+\mathrm{bV}_{\mathrm{s}}^{2}+\mathrm{bV}_{\mathrm{s}} \mathrm{E}_{2} \cos \left(\theta_{\mathrm{s}}\right)
\end{aligned}
$$

Here $\mathrm{b}=1 / \mathrm{X}_{2}$. The active $\left(\mathrm{P}_{\mathrm{sh}}\right)$ and reactive $\left(\mathrm{Q}_{\mathrm{sh}}\right)$ powers drawn by the shunt transformer are given by:

$\mathrm{P}_{\mathrm{sh}}=\Re\left[\mathrm{S}_{\mathrm{sh}}\right]=-\mathrm{V}_{\mathrm{m}} \mathrm{I}_{\mathrm{p}}$

$\mathrm{Q}_{\mathrm{sh}}=\mathfrak{I}\left[\mathrm{S}_{\mathrm{sh}}\right]=-\mathrm{V}_{\mathrm{m}} \mathrm{I}_{\mathrm{q}}$

As mentioned earlier that the net complex power exchange between a TCPST and the system is zero. The equality of real power balance between series and shunt transformer is given by:

$\mathrm{P}_{\mathrm{s}}=\mathrm{P}_{\mathrm{sh}}$

The in phase current $\left(\mathrm{I}_{\mathrm{p}}\right)$ of a shunt current injection can be written as:

$I_{p}=-b V_{s} \sin \left(\theta_{s}-\theta_{m}\right)+\frac{b V_{s} E_{2}}{V_{m}} \sin \left(\theta_{s}\right)$

Let:

$\frac{\mathrm{V}_{\mathrm{s}}}{\mathrm{V}_{\mathrm{m}}}=\mathrm{ae}^{\mathrm{j} \alpha}$ 


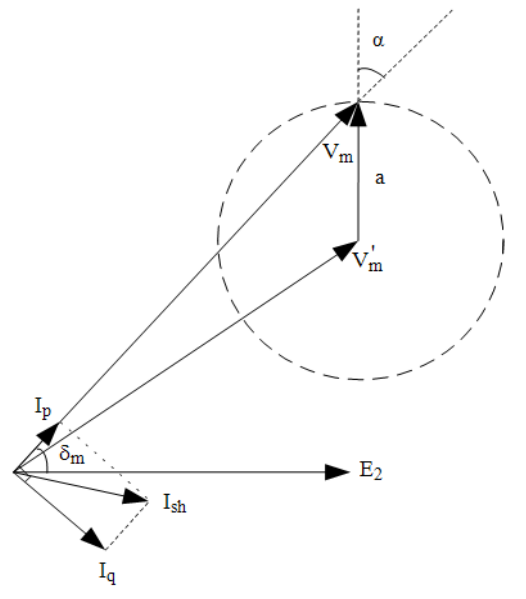

Fig. 3: Phasor of series injected voltage and shunt injected current of the TCPST

The size of a is related to the rating of a TCPS $\left(0<\mathrm{a}<\mathrm{a}_{\max }\right)$. The range of $\alpha$ depends on the type of TCPST. Now let the rage of $\alpha$ is $-\pi \leq \alpha \leq \pi$. Figure 3 shows the phasor diagram of a series injected voltage and shunt injected current.

Thus in phase current as given Eq. 8 is written as:

$I_{p}=-a b V_{m} \sin (\alpha)+a b E_{2} \sin \left(\theta_{m}+\alpha\right)$

Similarly, the balancing of reactive power exchange is given by:

$\mathrm{Q}_{\mathrm{s}}=\mathrm{Q}_{\mathrm{sh}}$

Thus the in quadrature current of a shunt current injection $\left(\mathrm{I}_{\mathrm{q}}\right)$ can be written as:

$\mathrm{I}_{\mathrm{q}}=a b V_{\mathrm{m}} \cos \alpha-\mathrm{a}^{2} b \mathrm{~V}_{\mathrm{m}}-\mathrm{abE_{2 }} \cos \left(\theta_{\mathrm{m}}+\alpha\right)$

The series injected voltage $\mathbf{V}_{\mathrm{s}}$ with $\mathrm{X}_{2}$ of Fig. $2 \mathrm{~b}$ can be transformed into the current $I_{s}$ as shown in Fig. 4a.

The value of $I_{s}$ is given by:

$\mathrm{I}_{\mathrm{s}}=\frac{\mathrm{V}_{\mathrm{s}}}{\mathrm{j} \mathrm{X}_{2}}=\mathrm{aV}_{\mathrm{m}} \mathrm{be} \mathrm{e}^{\mathrm{j}\left(\theta_{\mathrm{m}}+\alpha-90\right)}$

The current source connected between bus $\mathrm{m}$ and the infinite bus can be replaced by two shunt current source as shown in Fig. 4b. The net injected current $\left(\mathrm{I}_{\text {inj }}\right)$ at bus $\mathrm{m}$ can be written as:

$\mathrm{I}_{\mathrm{inj}}=\mathrm{I}_{\mathrm{sh}}+\mathrm{I}_{\mathrm{s}}$

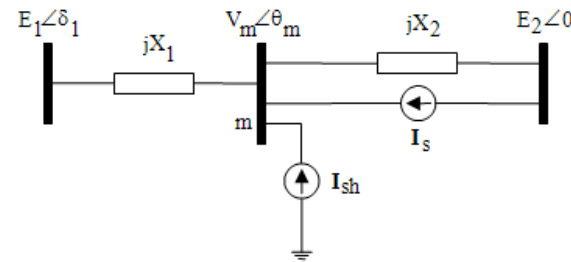

(a)

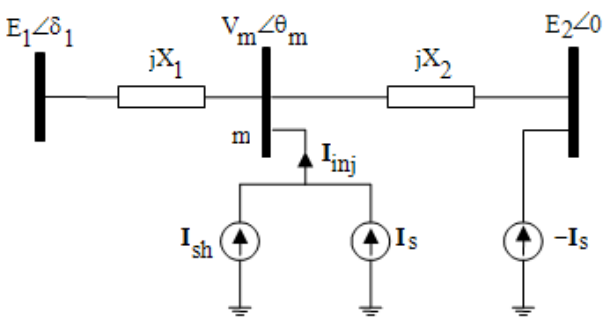

(b)

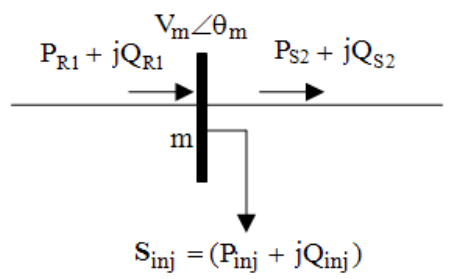

(c)

Fig. 4: Successive representation of series voltage source of the TCPST: (a) a series voltage source converted to a current source; (b) a net injected current model; (c) fictitious load model

The injected current $I_{\text {inj }}$ can further be replaced by a fictitious load $S_{\text {inj }}$ as shows in Fig. 4c. The value of the fictitious load is given by:

$\mathrm{S}_{\mathrm{inj}}=\mathrm{P}_{\mathrm{inj}}+\mathrm{Q}_{\mathrm{inj}}=\mathrm{V}_{\mathrm{m}}\left(-\mathrm{I}_{\mathrm{inj}}\right)^{*}$

The complex power of fictitious load power are given by:

$$
\begin{aligned}
\mathrm{P}_{\text {inj }} & =\Re\left[\mathrm{S}_{\text {inj }}\right]=-a b E_{2} \mathrm{~V}_{\mathrm{m}} \sin \left(\theta_{\mathrm{m}}+\alpha\right) \\
\mathrm{Q}_{\text {inj }} & =\mathfrak{I}\left[\mathrm{S}_{\mathrm{inj}}\right] \\
& =-2 a b V_{\mathrm{m}}^{2} \cos \alpha+\mathrm{a}^{2} b V_{\mathrm{m}}^{2}+a b E_{2} \mathrm{~V}_{\mathrm{m}} \cos \left(\theta_{\mathrm{m}}+\alpha\right)
\end{aligned}
$$

The active power balance equation at bus $m$ of Fig. 4c is given by:

$\mathrm{P}_{\mathrm{R} 1}=\mathrm{P}_{\mathrm{inj}}+\mathrm{P}_{\mathrm{s} 2}$ 
where, $P_{\mathrm{s} 1}=\frac{\mathrm{E}_{1} \mathrm{~V}_{\mathrm{m}}}{\mathrm{X}_{1}} \sin \left(\delta_{1}-\theta_{\mathrm{m}}\right)$ and $\mathrm{P}_{\mathrm{s} 2}=\frac{\mathrm{V}_{\mathrm{m}} \mathrm{E}_{2}}{\mathrm{X}_{2}} \sin \left(\theta_{\mathrm{m}}\right)$

After some mathematical manipulations of Eq. 17, the $\theta_{\mathrm{m}}$ of voltage at bus $\mathrm{m}$ can be expressed as:

$$
\theta_{\mathrm{m}}=\tan ^{-1}\left[\frac{\mathrm{X}_{2} \mathrm{E}_{1} \sin \delta_{1}+\mathrm{a} \mathrm{X}_{1} \mathrm{E}_{1} \sin (\alpha)}{\mathrm{X}_{2} \mathrm{E}_{1} \cos \delta_{1}-\mathrm{a} \mathrm{X}_{1} \mathrm{E}_{2} \cos (\alpha)+\mathrm{X}_{1} \mathrm{E}_{2}}\right]
$$

Similarly, the reactive power balance at bus $m$ of Fig. 4c is:

$\mathrm{Q}_{\mathrm{R} 1}=\mathrm{Q}_{\mathrm{inj}}+\mathrm{Q}_{\mathrm{s} 2}$

where, $Q_{R 1}=\frac{E_{1} V_{m}}{X_{1}} \cos \left(\delta_{1}-\theta_{m}\right)-\frac{V_{m}^{2}}{X_{1}}$ and

$\mathrm{Q}_{\mathrm{s} 2}=\frac{\mathrm{V}_{\mathrm{m}}^{2}}{\mathrm{X}_{2}}-\frac{\mathrm{V}_{\mathrm{m}} \mathrm{E}_{2}}{\mathrm{X}_{2}} \cos \left(\theta_{\mathrm{m}}\right)$

After some mathematical manipulation, the voltage magnitude at bus $\mathrm{m}$ is given by:

$$
\begin{aligned}
& \mathrm{V}_{\mathrm{m}}=1 /\left[\mathrm{X}_{1}+\mathrm{X}_{2}+\mathrm{a}^{2} \mathrm{X}_{1}-2 \mathrm{X}_{1} \mathrm{a} \cos (\alpha)\right]^{*} \\
& {\left[\mathrm{X}_{2} \mathrm{E}_{1} \cos \left(\delta_{1}-\theta_{\mathrm{m}}\right)-\mathrm{a} \mathrm{X}_{1} \mathrm{E}_{2} \cos \left(\theta_{\mathrm{m}}+\alpha\right)+\right.} \\
& \left.\quad \mathrm{X}_{2} \mathrm{E}_{2} \cos \left(\theta_{\mathrm{m}}\right)\right]
\end{aligned}
$$

It can be seen from the Eq. 18 and 20 that the TCPST placed at bus $\mathrm{m}$ impacts on both the voltage magnitude and the angle. It indicates that the voltage and the angle at bus $\mathrm{m}$ can be controlled by a series injected voltage. The electrical output power of generator $\left(\mathrm{P}_{\mathrm{e}}\right)$ is given by:

$$
P_{e}=\frac{E_{1} V_{m}}{X_{1}} \sin \left(\delta_{1}-\theta_{m}\right)
$$

The generator dynamics, in classical model of system, can be represented by following two first order differential equation:

$$
\dot{\delta}=\omega
$$

$\dot{\omega}=\frac{1}{\mathrm{M}}\left[\mathrm{P}_{\mathrm{m}}-\mathrm{P}_{\mathrm{e}}\right]$

Here $\delta, \omega, \mathrm{P}_{\mathrm{m}}, \mathrm{P}_{\mathrm{e}}$ and $\mathrm{M}$ are the rotor angle, speed, input mechanical power, output electrical power and inertia, respectively, of the generator. Solving the Eq. 22 and 23 yields the variation of $\delta$ and $\omega$ that can be used to study the dynamic behavior of the generator. Equation 23 clearly indicates that the output electrical power $\left(\mathrm{P}_{\mathrm{e}}\right)$ of the generator is the main factor that dictates the dynamic behavior of the generator because both $\mathrm{P}_{\mathrm{m}}$ and $\mathrm{H}$ are usually considered as constant. The proposed model of the TCPST indicates clearly that the $\mathbf{V}_{\mathrm{m}}$ can be controlled by a series injected voltage. Thus this proposed model of the TCPST is very easy to implement it to study its behavior on transient stability improvement of the simple system. However, the TCPST can help the system improve transient stability of the system when a series injected voltage is properly controlled. Thus the control strategy of a TCPST should be carefully designed.

Control strategy: This study uses the machine speed control parameters on a TCPST. When the speed deviation is positive $(\omega>0)$, the $\mathrm{P}_{\mathrm{e}}$ is raised by controlling parameters on TCPST; When the speed deviation is negative $(\omega<0)$, the $\mathrm{P}_{\mathrm{e}}$ is raised by controlling parameters on TCPST.

\section{RESULTS}

The presented mathematical model and control strategy is used to study the effect of TCPST on transient stability improvement of the system of Fig. 3. In all cases, it is considered that a three phase self clearing fault appears at bus $\mathrm{m}$ and the fault is cleared without changing the network configuration. Figure 5 shows the swing curve of the system without a TCPST for clearing time $\left(\mathrm{t}_{\mathrm{cl}}\right)=144 \mathrm{msec}$. Figure 6 shows the swings curve of the system with and without an TCPST for $\mathrm{t}_{\mathrm{cl}}=145 \mathrm{~m} \mathrm{sec}$.

\section{DISCUSSION}

From the results in Fig. 5 and 6, we found that the critical clearing time of the system without a TCPST is144-145 msec. It can be seen from the Fig. 5 that with fault clearing time $\left(\mathrm{t}_{\mathrm{cl}}\right)=144$, the system is considered as stable and the system is considered as unstable with $\mathrm{t}_{\mathrm{cl}}=145 \mathrm{msec}$ as can been in Fig. 6 .

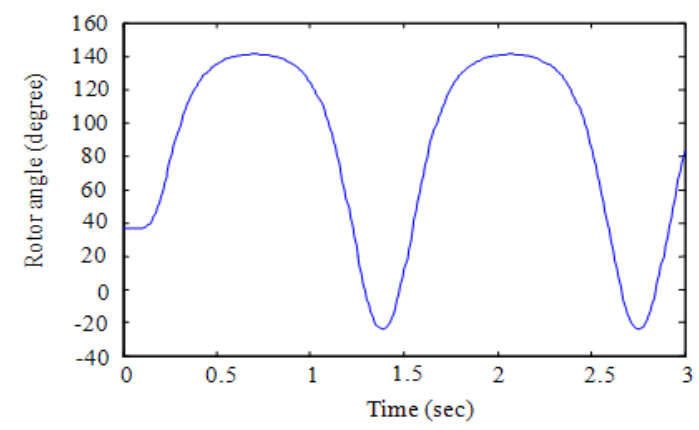

Fig. 5: Rotor angle of the system without TCPST for $\mathrm{t}_{\mathrm{cl}}=144 \mathrm{msec}$ 


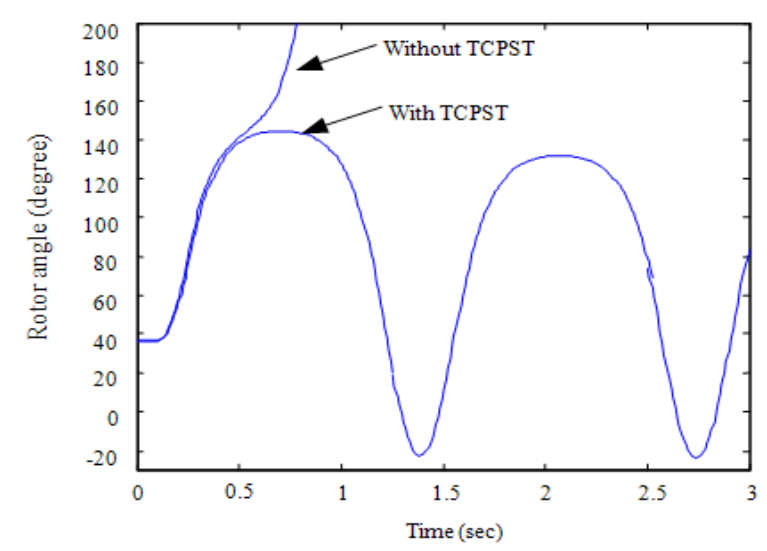

Fig. 6: Rotor angle of the system without and with an TCPST for $t_{c l}=145 \mathrm{msec}$

However, the system with a TCPST control can stabilize the system with $t_{c l}=145 \mathrm{msec}$. The simulation results indicate that a TCPST can improve stability of the system.

\section{CONCLUSION}

This study investigates the capability of the Thyristor Controlled Phase Shifter Transformer (TCPST) on transient stability improvement of the system. The mathematical model is systematically derived. The presented mathematical model has shown that power flow and stability of system can be regulated by TCPST. This study uses machine speed to control parameters on TCPST. The speed deviation is the main factor to decrease and increase power flow of the system. The simulation results are tested on Single Machine Infinite Bus (SMIB) system. From the simulation results, it indicates that a TCPST can improve transient stability of the system.

\section{REFERENCES}

Azbe, V. and R. Mihalic, 2008. The control strategy for an IPFC based on the energy function. IEEE Trans. Power Syst., 23: 1662-1609. DOI: 10.1109/TPWRS.2008.2004726

Badran, I., A.L. Mahmood and M.T. Lazim, 2008. Harmonics phase shifter for a three-phase system with voltage control by integral-cycle triggering mode of thyristors. Am. J. Applied Sci., 5: 15801587. ISSN: 1546-9239

Barbuy, H.S., A. Rocco, L.A.P. Fernandes and G.C. Guimaraes, 2009. Voltage collapse risk associated to under voltage capacitive compensation in electric power system operation. Am. J. Applied Sci., 6: 646-651. ISSN: 1546-9239
Bhownick, S., B. Das and N. Kumar, 2009. An advanced IPFC model to reuse newton power flow codes. IEEE Trans. Power Syst., 24: 525-532. DOI: 10.1109/TPWRS.2009.2016643

Daut, I., D.M.M. Ahmad, S. Zakaria, S. Uthman and S. Taib, 2006. comparison of losses and flux distribution in 3 phase $100 \mathrm{kVA}$ distribution transformers assembled from various type of $\mathrm{t}$-joint geometry. Am. J. Applied Sci., 3: 1990-1992. DOI: 10.3844/ajassp.2006.1990.1992

Hannan, M.A., A. Mohamed, A. Hussian and Majid al Aabby, 2009. Development of the unified series shunt compensator for power quality mitigation. Am. J. Applied Sci., 978-986. ISSN: 1546-9239

Leon, R.V.A. and L.C. Zanetta, 2008. A novel approach for modeling the steady state VSC based multiline FACTS controllers and their constrains. IEEE Trans. Power Syst., 23: 457-464. DOI: 10.1109/TPWRD.2007.905564

Magaji, N. and M.W. Mutafa, 2009. Optimal thyristor control series neuro-controller for damping oscillations. J. Comput. Sci., 5: 983-990. ISSN: 1549-3636

Parimi, A.M., I. Elamwazuthi and N. Saad, 2008. Interline Power Flow Controller (IPFC) based damping controllers for damping low frequency oscillations in a power system. Proceeding of the IEEE International Conference on Suitable Energy, Nov. 2008, Singapore, pp: 334-339. DOI: 10.1109/ICSET.2008.4747027

Zhang, X.P., 2003. Modeling of the interline power flow controller and the generalized unified power flow controller in Newton power flow. IEE Proc. Gener. Trans. Distrib., 150: 268-274. DOI: 10.1049/ip-gtd:20030093 